\title{
COLABORAÇÕES DE METODOLOGIAS ATIVAS PARA A MOTIVAÇÃO E PARA A APRENDIZAGEM DE ESTUDANTES NO ENSINO MÉDIO
}

\author{
Sâmara B. S. Faustinoㄴ, Vânia K. D. Ricardo², Daniel Aguiar da S. Oliveira Carvalho³
}

\section{PALAVRAS-CHAVE}

Metodologias Ativas;

Aprendizagem;

Motivação.

\begin{abstract}
RESUMO
Este capítulo trata das práticas formativas e experiências desenvolvidas enquanto bolsista residente do Programa de Residência Pedagógica (PRP), financiado pela Coordenação de Aperfeiçoamento de Pessoal de Nível Superior (CAPES), entidade vinculada ao Ministério da Educação (MEC). O objetivo é evidenciar a importância das metodologias ativas para os processos de ensino e de aprendizagem. Desejamos contribuir com as discussões sobre o campo da motivação de alunos na perspectiva da integração entre o saber sensível e o conhecimento inteligível para além dos aspectos tão somente cognitivos (SALOMÉ, 2011, p. 13). A experiência desta pesquisa aconteceu no curso da disciplina de Organização e Manutenção de Computadores, no Ensino Médio Integrado em Informática do Instituto Federal de Educação, Ciência e Tecnologia do Rio Grande do Norte (IFRN), campus Ipanguaçu, no ano de 2019.
\end{abstract}

\section{INTRODUÇÃO}

Historicamente, o Programa de Residência Pedagógica (PRP), surge sob diferentes nomenclaturas - Residência Educacional; Residência Pedagógica; Residência Docente - inspirado na Residência Médica ${ }^{4}$, a qual estabelece um processo de imersão na prática formativa como parte do processo de aprendizagem da profissão.

A Residência Educacional foi uma proposição do ex-senador Marco Maciel (DEM/PE) por meio do Projeto de Lei do Senado (PLS) $n^{\circ}$ 227, de 2007. Após cinco anos, o ex-senador Blairo Maggi (PR-MT), mediante o PLS n ${ }^{\circ} 284 / 2012$, trouxe a

\footnotetext{
${ }^{1}$ Graduanda do Curso Superior de Licenciatura em Informática no Instituto Federal de Educação, Ciência e Tecnologia do Rio Grande do Norte (IFRN) - Campus Ipanguaçu. E-mail: samarasugimoto@ live.com

${ }^{2}$ Graduanda do Curso Superior de Licenciatura em Informática no Instituto Federal de Educação, Ciência e Tecnologia do Rio Grande do Norte (IFRN) - Campus Ipanguaçu. E-mail: vaniakarladr@ hotmail.com

${ }^{3}$ Professor Efetivo do Instituto Federal de Educação, Ciência e Tecnologia do Rio Grande do Norte (IFRN) - Campus Ipanguaçu. Formado em Tecnologia em Análise e Desenvolvimento de Sistemas (IFRN) com Mestrado em Sistemas e Computação pela Universidade Federal do Rio Grande do Norte (UFRN). E-mail: daniel.aguiar@ifrn.edu.br

${ }^{4}$ Instituída pelo Decreto $\mathrm{n}^{\circ}$ 80.281, de 5 de setembro de 1977, é uma modalidade de ensino de pós-graduação destinada a médicos, sob a forma de curso de especialização. Maiores detalhes consultar http://www.planalto.gov.br/ccivil_03/decreto/1970-1979/D80281.htm.
} 
denominação de Residência Pedagógica, com a finalidade de melhorar as condições da Educação Básica, através de

[...] uma etapa ulterior de formação inicial para a docência na Educação Infantil e nos primeiros anos do Ensino Fundamental, na forma da 'residência', remunerada por meio de bolsas de estudos e com carga horária mínima de 800 horas. (TERRA, 2013, p. 36).

Esse Programa foi alvo de críticas por especialistas, por ser voltado apenas para as modalidades da Educação Infantil e do Ensino Fundamental, assim como por oferecer uma bolsa com um valor pequeno e uma carga horária grande (800 horas), o que desestimularia os alunos residentes ao tornar precárias as condições de trabalho (TERRA, 2013).

Nesse mesmo ano, o Colégio Pedro II, localizado no estado do Rio de Janeiro, instituiu o Programa Residência Docente, que se caracteriza como uma realização de Terceiro Espaço na formação de professores, tendo a finalidade de oferecer a professores recém-formados uma inserção em um projeto que contempla pesquisa, teoria e prática para o aprimoramento do exercício da docência e culmina na concessão do título de especialista. (SANT'ANNA; MATTOS; COSTA, 2015).

Em 2018, por meio da Portaria $n^{0} 38$, a Coordenação de Aperfeiçoamento de Pessoal de Nível Superior (CAPES), fundação vinculada ao Ministério da Educação (MEC), instituiu o Programa de Residência Pedagógica (PRP), tendo como público alvo os alunos dos cursos de licenciatura e a finalidade de apoiar Instituições de Ensino Superior (IES) na implementação de projetos inovadores que estimulem a articulação entre teoria e prática nos cursos de licenciatura, conduzidos em parceria com as redes públicas de educação básica. (BRASIL, 2018a).

A Portaria CAPES n 45/2018, estabeleceu que no PRP o estudante poderá ser bolsista residente a partir do $5^{\circ}$ período ou caso já tenha cursado o mínimo de $50 \%$ da graduação, estando com a matrícula ativa em algum curso de licenciatura. Dessa forma, o bolsista residente compromete-se com uma carga-horária de 440 horas de atividades voltadas à formação docente (BRASIL, 2018b).

Para Giglio e Lugli (2013 apud FAUSTINO et al., 2019), o PRP tem em sua concepção inicial a superação das limitações dos estágios curriculares supervisionados. E Silva e Cruz (2018, p. 236), acrescentam que “o programa não se limita somente à vivência em sala de aula, mas busca constituir uma interação entre pesquisa acadêmica e teoria-prática docente". Ou seja, trata-se de um Programa educacional que tem por objetivo a construção de conhecimento por meio das relações contínuas entre a teoria e a prática.

Segundo Faustino et al. (2019), o PRP, integrando-se à Política Nacional de Formação de Professores, proporciona o aperfeiçoamento da formação docente, mediante as ações de imersão e intervenção do licenciando na escola-campo. 
Assim, neste capítulo trataremos do relato das experiências de imersão e regência nas práticas formativas das graduandas do curso de Licenciatura Plena em Informática, do Instituto Federal de Educação, Ciência e Tecnologia do Rio Grande do Norte, campus Ipanguaçu (IFRN-Campus Ipanguaçu), desenvolvidas por meio do PRP.

\section{DESENVOLVIMENTO}

Esta pesquisa adota a abordagem qualitativa, que se preocupa em fazer análise, interpretar os dados a serem estudados (MARCONI; LAKATOS, 2011) e tem por enfoque a pesquisa-ação, na qual o pesquisador participa, interage, acompanha e realiza mediações de ações envolvidas (SEVERINO, 2007).

As experiências a seguir relatadas foram vivenciadas na disciplina de Organização e Manutenção de Computadores, com a turma do $3^{\circ}$ ano do Ensino Médio Integrado em Informática do IFRN, Campus Ipanguaçu enquanto escolacampo), no ano letivo de 2019. A turma contempla 22 alunos, com faixa etária entre 17 e 19 anos, sendo $77 \%$ do gênero masculino e $23 \%$ do feminino.

\section{Metodologias Ativas para a formação humana transformadora}

Segundo Tardif (2002), o desenvolvimento do saber (saber-fazer e saber-ser) é oriundo da competência profissional do docente que provém das raízes ao longo de sua história de vida e dos saberes adquiridos durante toda a trajetória de vivências pessoais, acadêmicas, profissionais, socializações e práticas cotidianas do próprio exercício da docência.

Dessa forma, pode-se dizer que a formação inicial não é suficiente, pois são os contextos de urgências e de adaptação intensa que ajudam o processo formativo quando os professores ficam imersos na realidade do ambiente escolar, o que possibilita a construção de uma bagagem de conhecimentos anteriores e posteriores do fazer docente, articulando a formação universitária com a formação continuada.

Sendo assim, o PRP tem o papel de socializar os conhecimentos constituídos em uma trajetória pré-profissional, agregando valor à formação inicial do graduando, proporcionando vivências do elo entre teoria e prática, sendo necessário o processo de adaptação para solucionar os problemas ou dificuldades a serem enfrentados, assim como os impactos da prática do magistério. Sob outra perspectiva, Panizzolo et al. (2012, p. 228) destacam que:

Ao mesmo tempo em que o período de imersão propicia o contato sistemático com a realidade educacional e escolar, revela situações, muitas vezes, tendentes à imobilização e ao desânimo, além da predominância da crítica aos processos e aos profissionais de ensino, dada as difíceis condições da escola pública brasileira. O desafio que se coloca dirige-se, novamente, à reflexão, à observação criteriosa, ao olhar investigador e ao incentivo à conscientização dos Residentes para a construção de um posicionamento ético e para as possibilidades de atuação profissional e não apenas para a constatação dos problemas evidentes. 
Nesse sentindo, o PRP propicia voz e vez aos residentes "para as suas concepções e experiências no cotidiano escolar, permitindo assim que os conhecimentos apreendidos nas salas da universidade sejam colocados em prática." (SILVA, 2015, p. 25).

No que tange à sociedade contemporânea, é notório que aos poucos se mudam as vertentes educacionais, no qual "a educação formal está num impasse diante de tantas mudanças [...] como evoluir para tornar-se relevante e conseguir que todos aprendam de forma competente a conhecer" (MORAN, 2015, p.15).

Os processos de ensino e de aprendizagem envolvem toda a complexidade motivacional em sala de aula, no qual a escola e principalmente o educador devem saber lidar com o educando, um ser humano que possui uma bagagem repleta de conhecimentos, experiências e vivências distintas. Por isso, é importante sabermos

[...] valorizar seus conhecimentos prévios, trabalhar a partir deles, estimular as potencialidades dando a possibilidade de este aluno superar suas capacidades e ir além ao seu desenvolvimento e aprendizado. Para que o professor possa fazer um bom trabalho ele precisa conhecer seu aluno, suas descobertas, hipóteses, crenças, opiniões desenvolvendo diálogo criando situações onde o aluno possa expor aquilo que sabe. (COELHO; PISONI, 2012, p. 150).

A aprendizagem trata de um processo contínuo, por isso Vygotsky defende em suas teorias de aprendizagem, que é no contexto social que ocorre o desenvolvimento cognitivo. Segundo Coelho e Pisoni (2012, p. 150),

[...] a teoria de Vygotsky parece ser revolucionária diante da nossa realidade, mas busca aquilo que o homem tem de melhor: sua criatividade, sua autonomia, sua condição de sujeito ativo e não de objeto a ser moldado. É um erro pensar a educação como algo deslocado da vida cotidiana, para que ocorra uma educação de verdade é necessário que esta seja transformadora no sentido de promover o respeito pela diferença, não homogeneizar padronizando a todos.

Diante de tantas mudanças evolutivas socioculturais e tecnológicas que a sociedade vem enfrentando, na escola não é diferente. Atualmente, apesar do ensino ainda ser predominantemente tradicional, faz-se necessário adaptá-lo com metodologias para atender as demandas atuais dessa sociedade que vive em constantes mudanças e que exigem competências cognitivas pessoais e sociais. Dessa forma, o ensino deve ser crítico-reflexivo seguindo as nuances de abordagens pedagógicas como são enfatizadas por Freire, Vygotsky, Wallon, Waldorf entre outros, visando proporcionar ao aluno o desenvolvimento da "proatividade, colaboração, personalização e visão empreendedora." (MORAN, 2015, p. 16).

Essas atribuições do conhecimento não são adquiridas pelos métodos convencionais que privilegiam a transmissão do conhecimento e tem por foco ensinar e avaliar todos igualmente, com o olhar apenas no resultado da avaliação, sem 
considerar as inteligências múltiplas e que cada aluno tem o seu ritmo próprio de aprendizagem.

Assim, as Metodologias Ativas surgem como uma nova proposta do paradigma educacional, que se contrapõe ao modelo tradicional de ensino. Pode-se dizer que essas Metodologias constituem um conjunto de ações, no qual envolve a postura do educador, a forma de avaliação, a valorização dos conhecimentos e as experiências do aluno, tendo como característica a inserção do aluno como sujeito ativo, responsável pela própria aprendizagem e o professor como mediador desse processo de ensinar e aprender. (PEIXOTO, 2016). Ou seja,

[...] o professor é o mediador, e principal responsável pela seleção dos conteúdos voltados ao processo de ensino-aprendizagem, mas cada aluno mesmo com suas particularidades e desafios, é o principal sujeito do processo educativo, dependendo somente dele e os meios para efetivar a aprendizagem, $\log$ o é necessário que o aluno seja ativo e busque a autonomia do aprender. (RICARDO et al., 2018, p. 05).

Essa estratégia de ensino baseia-se na personalização da aprendizagem e surge com a finalidade de superar a educação bancária, pois as Metodologias Ativas são pontos de partida para os "processos mais avançados de reflexão, de integração cognitiva, de generalização, de reelaboração de novas práticas." (MORAN, 2015, p. 18).

As Metodologias Ativas, com início na década de 1980, procuraram dar
resposta à multiplicidade de fatores que interferem no processo de
aprendizagem e à necessidade dos alunos desenvolverem habilidades
diversificadas. Era necessário que o aluno adquirisse um papel mais ativo e
proativo, comunicativo e investigador. De certa maneira, essas metodologias
opõem-se a métodos e técnicas que enfatizam a transmissão do
conhecimento. Elas defendem uma maior apropriação e divisão das
responsabilidades no processo de ensino-aprendizagem, no relacionamento
interpessoal e no desenvolvimento de capacidade para a autoaprendizagem.
O papel do professor foi também repensado; passou de transmissor do
conhecimento para monitor, com o dever de criar ambientes de
aprendizagem repleto de atividades diversificadas. (MOTA; WERNER DA
ROSA, 2018, p.263).

Considerando o panorama atual de um mundo globalizado, com os céleres avanços tecnológicos e o fácil acesso à informação, a geração 2000 é marcada pelas interações com as tecnologias digitais e redes sociais, no qual as tecnologias computacionais e da internet estão presentes no cotidiano, constituindo assim, uma geração de pessoas que "são autoconfiantes, acreditam em si mesmo, desejam sucesso financeiro, independência pessoal, gostam de trabalhar em equipe e são imediatistas" (SILVA; BORGES, 2013, p. 3).

Consequentemente, um dos principais desafios do docente em sala de aula é de motivar e tornar interessante os conteúdos curriculares. Todavia, atualmente, os conteúdos de várias áreas do conhecimento que antes eram disponibilizados apenas 
por meios físicos (livros, jornais e revistas), estão completamente acessíveis por meios digitais. À vista disso, compreende-se que

Os métodos tradicionais, que privilegiam a transmissão de informações pelos professores, faziam sentido quando o acesso à informação era difícil. Com a Internet e a divulgação aberta de muitos cursos e materiais, podemos aprender em qualquer lugar, a qualquer hora e com muitas pessoas diferentes. Isso é complexo, necessário e um pouco assustador, porque não temos modelos prévios bem-sucedidos para aprender de forma flexível numa sociedade altamente conectada. (ALMEIDA; VALENTE, 2012 apud MORAN, 2015, p. 16).

Embora as Tecnologias Digitais de Informação e Comunicação (TDIs) causem receios quanto a sua utilização na educação, no sentido de substituírem o professor, podemos afirmar que, no processo de construção do conhecimento, o professor é insubstituível e tem um papel importantíssimo no processo formativo do aluno, uma vez que os "recursos tecnológicos por si só não criam aprendizagens significativas" (ENS, 2002, p. 38). Na realidade, conforme evidencia Moran (2015, p. 16), a tecnologia quando bem utilizada é responsável por trazer uma integração de todos os espaços e tempos, pois

[...] o ensinar e aprender acontece numa interligação simbiótica, profunda, constante entre o que chamamos mundo físico e mundo digital. Não são dois mundos ou espaços, mas um espaço estendido, uma sala de aula ampliada, que se mescla, hibridiza constantemente. Por isso a educação formal é cada vez mais blended, misturada, híbrida, porque não acontece só no espaço físico da sala de aula, mas nos múltiplos espaços do cotidiano, que incluem os digitais. O professor precisa seguir comunicando-se face a face com os alunos, mas também digitalmente, com as tecnologias móveis, equilibrando a interação com todos e com cada um.

Assim, concordamos com Oliveira (2015, p. 80) quando assevera que a inserção das TDICs nos processos de ensino e aprendizagem proporciona novas possibilidades de saberes, desenvolvendo o "pensamento crítico criativo e a aprendizagem cooperativa, uma vez que torna possível a realização de atividades interativas."

Ressaltamos a necessidade dos professores em buscar metodologias e estratégias de ensino que edificam a aula e proporcionam uma experiência significativa do fazer docente nos processos de ensino e aprendizagem, considerando o espaço e contexto escolar, de forma a contribuir para o saber sistematizado do educando (SAVIANI, 2005).

Certamente, a era digital traz uma ressignificação para professor, o qual não é mais o detentor e principal responsável pela transmissão do conhecimento e, sim, um mediador que deve saber admitir não possuir todas as respostas, pois assim como o aluno, ele também está em um processo de aprendizado contínuo. 


\title{
Documentários e Debates em Sala de Aula
}

O uso de documentário em sala de aula possibilita uma maior imersão do aluno durante a aula, através do estímulo da capacidade de percepção visual e imaginativa, que contribuem significativamente para os aspectos cognitivos no processo de aprendizagem (BATISTA; NUNES, 2018).

Em pensamento alinhado, Moran (1995, p. 29), afirma que "a linguagem audiovisual desenvolve múltiplas atitudes perceptivas: solicita constantemente a imaginação e reinveste a afetividade com um papel de mediação primordial no mundo". No mesmo sentido, Sales aduz,

\begin{abstract}
Alguns podem considerar uma forma de pouco praticidade para o uso do documentário em sala de aula, contudo a proposta é apresentar ao aluno uma forma de "ler" a história e entende-la, compreendendo que a "realidade" não é dicotômica, não é branco e preto, mas que contem tons de cinza. Compreender estes tons de cinza é o que vai proporcionar que o aluno desenvolva uma capacidade de criticidade tão almejada pelas leis brasileiras. Não basta criticar por criticar, mas dar ferramentas e meios para que o aluno tenha uma crítica consistente, observando sua realidade e o que o cerca. Entender o lugar de fala de quem produz, seja a história, seja um filme ou o livro didático. Proporcionar tais meios é, afinal, o papel do professor em sala de aula. (SALES, 2009, p.06).
\end{abstract}

Portanto, os documentários não são apenas ilustrações que induzem a ludicidade, mas sim um tipo de recurso midiático que quebra a rotina de uma aula expositiva, diversificando o processo de ensino e aprendizagem, trazendo dinamismo para a aula como um complemento sobre o assunto ministrado. Todavia, "não é satisfatório didaticamente exibir o vídeo sem discuti-lo, sem integrá-lo com o assunto de aula, sem voltar e mostrar alguns momentos mais importantes" (MORAN, 1995, p. 30).

De acordo com Coelho e Viana (2011, p.94), a avaliação "pode ocorrer por meio de um debate em sala de aula, ou da contextualização do conteúdo que foi explorado na atividade, em pesquisas, redações, apresentação de seminários, ou mesmo numa reflexão do professor".

Na nossa experiência, o primeiro documentário aplicado com a turma, em março de 2019, foi The Light Bulb Conspiracy (A conspiração da lâmpada). Um documentário que apresenta a realidade que ocorre especialmente nos bastidores da indústria tecnológica. O título é decorrente de uma estratégia da obsolescência programada, que se iniciou na década de 1920, com um cartel que reuniu fabricantes de todo o mundo, na cidade de Genebra, para decidirem que a lâmpada teria uma redução da sua durabilidade, contrapondo-se a qualidade da lâmpada centenária que está acesa desde 1901, em Livermore.

A obsolescência programada surgiu simultaneamente entre a produção em massa e a sociedade do consumo, estando por trás dos processos de fabricação dos produtos que são comercializados com uma redução da durabilidade. Ou seja, são 
programados para quebrarem e, assim, estimular o consumismo e aumentar as vendas e os lucros dos capitalistas. Com isso a sociedade é de fato vítima desse complô, pois "trata-se de uma lógica perversa, cujo dogma impõe que se as pessoas não comprarem a economia não vai crescer." (SANTOS; DOMINIQUINI, 2014, p. 53).

Muitos exemplos foram apresentados no decorrer do documentário para mostrar como, historicamente, evoluiu a obsolescência programada - que vai desde o caso das lâmpadas, passando pela invenção do Nylon com a criação de meias com fios de alta resistência e durabilidade (sonho de consumo de todas as mulheres) que foram "reprogramadas" para diminuírem a durabilidade, até tempos bem recentes, com o famoso caso da primeira geração do iPod em que um artista de Nova York, pagou US\$ 500 por um iPod cuja bateria parou de funcionar oito meses depois e, quando foi reclamar, a resposta da Apple foi de que valeria a pena comprar um novo. $\mathrm{O}$ caso gerou passeata e ação coletiva na justiça. Outro exemplo importante para análise trazido pelo documentário é o caso dos primeiros carros da Ford que eram verdadeiros "tratores" de tão fortes. A Chevrolet não tendo como competir com os motores da Ford em termos de durabilidade e qualidade vai operar com uma nova faceta da obsolescência programada: o design. Assim, a Ford tinha motor, mas a Chevrolet o design e, a cada novo design, o anterior ficava "velho" exigindo a troca em períodos cada vez mais curtos. O forte e velho modelo da Ford não tinha mais lugar no mercado. Infere-se do exemplo acima citado que a obsolescência programada não diz respeito apenas à durabilidade ou funcionalidade do produto - muitas formas estão juntas - desde a tecnológica pura à forma psicológica, na qual, para "ser feliz" o consumidor precisa adquirir o "último modelo" de qualquer coisa para seguir a moda, ou para satisfazer uma nova necessidade criada pelo mercado no "mundo das necessidades fabricadas". As consequências da obsolescência programada também são exploradas pelo documentário, e a principal delas é a montanha de lixo gerada e enviada para os países pobres, no caso apresentado, o envio do lixo eletrônico para Gana onde são gerados inúmeros problemas socioambientais, entre eles, a poluição de rios que são base de subsistência de pessoas, através da pesca. (SILVA, 2012, p. 5437).

Com este documentário, foi possível evidenciar o quanto e como a obsolescência programada está presente em nossas vidas, entre os paradigmas da evolução de um sistema que torna os produtos descartáveis pela baixa durabilidade e um sistema que leva o consumidor a substituir esses produtos pelo simples desejo do novo, seja por design ou pela tecnologia, induzindo ao consumo demasiado e inconsciente, por vezes, desnecessário.

Para avaliar os assuntos abordados no documentário promovemos um debate com os alunos, organizando, na sala de reuniões da escola-campo, um plenário diante de um júri, sendo a sala dividida entre os que são a favor da obsolescência programada e os que são contra. O debate foi profícuo, pois certamente contribuiu para a formação cidadã e para a leitura de mundo de nossos alunos.

De acordo com Altarugio, Diniz e Locatelli (2010, p. 28),

O debate, como estratégia, provê um ambiente propício para que os alunos aprendam a argumentar, isto é, que se tornem capazes de reconhecer as 
afirmações contraditórias e aquelas que dão suporte às afirmações. Da mesma forma, é importante que os alunos percebam que as ideias, quando debatidas coletivamente, podem ser reformuladas por meio da contribuição dos colegas. O movimento da troca de ideias e da construção de conhecimentos é reforçado durante um debate e, desse modo, os alunos têm a chance de compreender melhor o caráter coletivo e dinâmico do trabalho científico. Todo esse exercício contribui muito para a formação do cidadão crítico, capaz de tomar decisões relevantes frente aos problemas sociais. Tanto a construção de argumentos consistentes a partir do relacionamento de informações, representadas de diferentes formas, e de conhecimentos disponíveis em situações concretas, quanto o uso dos conhecimentos desenvolvidos na escola para elaboração de propostas de intervenção solidária na sociedade, são competências que encontramos nos eixos teóricos que estruturam o Exame Nacional do Ensino Médio - ENEM.

Ressaltamos que são diversas as possibilidades de se trabalhar com documentários em sala de aula, uma delas é o debate, que permite ao professormediador analisar e avaliar a capacidade do aluno em relação à reflexão crítica, à crítica construtiva, à desenvoltura, o ponto de vista, os argumentos, o comportamento e à participação de cada aluno frente ao assunto em questão. Outra é trabalhar algumas competências exigidas no mercado de trabalho, que é embasado em dinâmicas de grupo.

O segundo documentário aplicado com a turma, foi A definição do humano: impactos da tecnologia, no qual foi proposto um novo debate, considerando a alta aceitação e participação dos alunos no debate anterior. Para este debate, cada aluno assumiu o papel representativo de embaixador/ministro dos seguintes países: Brasil; Venezuela; Chile; Argentina; Paraguai; Estados Unidos; Canadá; China; Japão; Coreia do Norte; África do Sul; Angola; Israel; Somália; Palestina; França; Inglaterra; Alemanha e Rússia, todos vinculados à Organização das Nações Unidas (ONU), em uma reunião representativa oficial diante do secretário de defesa, secretário de comércio e secretário geral, tendo por objetivo conhecer os avanços tecnológicos e sua importância em cada país e propor soluções referentes aos impactos da tecnologia no contexto social, cultural, educacional, econômico, industrial e ambiental. O debate foi gravado no formato audiovisual $\mathrm{mp} 4$, para posteriormente avaliar a interação, estratégias e movimentos argumentativos de cada um.

\section{A Aula de Campo para a construção de Conhecimentos}

A aula de campo possibilita novos conhecimentos, ao valorizar a individualidade de cada aluno, pois se trata de uma ferramenta didática que contribui para a superação do desafio da desmotivação dos alunos diante de uma aula expositiva, assim como, considera as necessidades de diversificação da aula para atender as inteligências múltiplas de cada um, permitindo ao aluno novas experiências, habilidades e conhecimentos que nem sempre são incentivadas na aula tradicional. (ZORATTO; HORNES, 2014). 
De acordo com esses autores, a aula de campo aproxima "a teoria da realidade, vincula a leitura e a observação, situações e ações que, associadas à problematização e à contextualização encaminhadas pelo docente, ampliam a construção do conhecimento pelo aluno" (ZORATTO; HORNES, 2014, p. 2). Portanto, o processo de ensino e aprendizagem em ambientes não formais de educação proporciona melhorias significativas no ensino de forma mais lúdica, dinâmica e atrativa, instigando o aluno na construção formativa do aprendizado.

Por meio de uma visita técnica à Superintendência da Polícia Rodoviária Federal do Rio Grande do Norte (PRF-RN) ${ }^{5}$, foi possível proporcionar aos alunos do $3^{\circ}$ ano do Ensino Médio Integrado em Informática, uma aula de campo com o objetivo de conhecerem de perto outra possibilidade profissional. Essa aula de campo foi uma vivência única que oportunizou aos alunos conhecerem às áreas de comunicação e informação da corporação, como: sistemas operacionais, equipamentos, centro de processamento de dados, centro de comando e controle. E faltando apenas um ano, para enfim decidirem a formação que pretendem seguir, foi relevante também a visita à Universidade Federal do Rio Grande do Norte (UFRN), no qual os alunos puderam conhecer alguns setores, como a subestação elétrica.

Estas ações reforçam a nossa concordância com Seniciato e Cavassan (2004, p. 140), quando afirmam que "o ensino pautado somente nas ideias, no abstrato e, sobretudo, na fragmentação do conhecimento tem contribuído para um desânimo, uma indiferença e um desprezo em relação ao conhecimento". Logo, a aula de campo possui um viés motivacional, que instiga o olhar crítico do aluno, o detalhamento do espaço ao seu redor, possibilitando o processo de assimilação dos conteúdos estudados em sala de aula, indo além de uma aula teórica expositiva. (MONTEIRO; SANTOS, 2015).

\section{O Kahoot como Instrumento Avaliativo}

As tecnologias gradativamente modificam o ambiente social, profissional e educacional. Dessa forma, a utilização das TDICs nestes contextos é uma necessidade inadiável, pois as tecnologias estão cada vez mais presentes no cotidiano das pessoas e "com o rápido avanço da internet é oportuno utilizar estratégias de ensino e recursos tecnológicos em sala de aula." (NEVES; FAUSTINO; ARAÚJO, 2018, p. 1).

O Kahoot 6 é uma plataforma disponibilizada de forma online, acessível via web browser e mobile app, baseada em jogos que contribui ludicamente e dinamiza o processo do ensino e do aprendizado do conteúdo, o que traz reflexos significativos e imediatos relacionados à receptividade em sala de aula, proporcionando uma melhoria na motivação dos alunos e interação social.

\footnotetext{
${ }^{5}$ Disponível em: https://www.prf.gov.br/agencia/superintendencia-da-prf-no-rn-recebe-alunos-doifrn-de-ipanguacu/

${ }^{6}$ Disponível em: https://kahoot.com/
} 
Essa interação social em sala de aula permite uma maior participação dos alunos, tornando a aula diferente do habitual. No entanto, a presença do docente e a ressignificação do jogo ao contexto do conteúdo, é fundamental, para que os aparatos tecnológicos possam dinamizar e trazer significado ao aprendizado do discente. (FAUSTINO et al., 2019, p. 2).

É perceptivo que os nativos digitais são imersos no mundo digital, estando diariamente conectados às diversas tecnologias, sendo uma delas, a gamificação. Desde cedo, ainda em uma fase imatura, as crianças estão expostas a essa realidade do mundo contemporâneo, sendo uma forma de entretenimento, com o propósito de distrair e divertir a criança. Segundo Ribeiro (2017, p. 9), “esses são os que cresceram cercados por tecnologias digitais e que não podem ser limitados por uma escola cerrada entre quatro paredes e que não lhes permite vislumbrar o alcance de novas ferramentas que ajudem na aprendizagem".

Nesta perspectiva, percebe-se que os jogos têm um papel motivacional, que contribui para o engajamento dos indivíduos nos diversos contextos e ambientes socioeducacionais (ZICHERMANN; CUNNINGHAM, 2011). A partir da gamificação é possível trabalhar várias competências, como por exemplo criatividade, habilidade, agilidade, raciocínio lógico, entre outros. Sendo possível também trabalhar os conteúdos de diversas áreas do conhecimento, mas para isso, é necessário que o professor saiba direcionar o jogo para o objetivo da aula. De acordo com Moran (2015), os jogos são repletos de desafios, recompensas, estratégias, etapas, competições e cooperações, atributos que são atraentes para os alunos desenvolverem habilidades em diversas áreas do conhecimento, níveis e modalidades de ensino.

\section{CONSIDERAÇÕES FINAIS}

Nas práticas educacionais e na realidade escolar nos deparamos com uma complexidade de concepções de mundo, sociedade e educação que, por vezes, induzem ao engessamento das metodologias de ensino, e que deixa o professor, aluno e escola em uma situação de difícil percepção entre a convergência e divergência do ensinar e educar sob outras perspectivas, como as das Metodologias Ativas ou da utilização das TDICs no ambiente escolar.

Neste contexto, o ensino deve ser pensado para além dos aspectos cognitivistas, buscando outras possibilidades de trabalhar a formação humana e crítica do aluno frente ao ambiente que o cerca, despertando assim, a capacidade de sair desta anestesia em que se situa o ensino tradicional, que é voltado ao desenvolvimento das habilidades "meramente cognitivas, numa razão cientificista que não leva em consideração o sentir" (SALOMÉ, 2011, p. 12).

Mudar e propor algo inovador, que possa despertar o interesse dos estudantes pelas aulas é o desafio que nos cabe. Pensar em alternativas em que o acadêmico assuma postura mais participativa, em que ele resolve problemas, participa do desenvolvimento e gestão de projetos, criando mais 
oportunidades para a construção do conhecimento. E, sobretudo, possibilite a ele o risco de errar, de falhar e de estudar problemas que existem no ambiente corporativo. (DIAS; CHAGA, 2017, p. 46).

São inúmeras as contribuições das metodologias, técnicas e ferramentas de ensino, que torna o aluno como sujeito ativo e busca trazer significado ao aprendizado, sendo uma oportunidade que o aluno tem de experimentar novas sensações, sendo motivada à aprendizagem significativa e ao professor a oportunidade de diversificar e dinamizar a sua aula, dando voz aos seus educandos.

Como resultado da realização de nossas experiências enquanto bolsistas residentes, destacamos a gratidão por todos os momentos vivenciados na escolacampo por meio do PRP, que proporcionou mediante as metodologias ativas desenvolvidas, uma ressignificação do pensar e de fazer para a docência com um olhar ampliado para a realidade escolar. Foi fascinante proporcionar significado para a aprendizagem dos alunos.

Além disso, nos permitiu refletir sobre as propostas e as contribuições que podem transcender de forma positiva para a vida acadêmica dos alunos. As mediações foram motivadoras, permitiram aprendizagem contínua e o desenvolvimento de leitura crítica do mundo. Adicionalmente, pretendemos estudar e desenvolver trabalhos futuros voltados para as Metodologias Ativas, com o enfoque na participação e motivação dos alunos nos mais variados espaços educacionais.

\section{REFERÊNCIAS}

ALTARUGIO, M. H.; DINIZ, M. L.; LOCATELLI, S. W. O Debate como Estratégia em Aulas de Química. Química Nova na Escola, v. 32, p. 26-30, 2010.

BATISTA, D. F.; NUNES, J. V. O Uso de Documentários como Ferramenta Didática no Ensino de Biblioteconomia. REBECIN, v. 5, n. 2, p. 47-62, jul./dez. 2018.

BRASIL. Ministério da Educação. CAPES. Portaria $\mathbf{n}^{0}$ 38, de 28 de fevereiro de 2018. Brasília, DF, 2018a. Disponível em: <https:/ / capes.gov.br/images/stories/download/legislacao/28022018-Portaria_n_ 38 -Institui_RP.pdf>. Acesso em: 11 out. 2019.

BRASIL. Ministério da Educação. CAPES. Portaria $\mathbf{n}^{\circ} \mathbf{4 5}$, de 12 de março de 2018. Brasília, DF, 2018b. Disponível em: <https:/ / capes.gov.br/images/stories/download/legislacao/16032018_Portaria_45 _Regulamento_PIBID_e_Residencia_Pedagogica_SITE.pdf>. Acesso em: 11 out. 2019.

COELHO, R. M. de F.; VIANA, M. da C. V. A Utilização de Filmes em Sala de Aula um Breve Estudo no Instituto de Ciências Exatas e Biológicas da UFOP. Revista da Educação Matemática da UFOP. v. 1, p. 89 - 97, 2011. 
COELHO, L.; PISONI, S. Vgotsky: sua teoria e a influência na educação. Revista ePed-FACOS/CNEC, Osório, v. 2, n. 1, ago. 2012.

DIAS, S. R.; CHAGA, M. M. Aprendizagem Baseada em Problema: um Relato de Experiência. In: MACHADO, Andreia de Bem et al.(Org.). Práticas Inovadoras em Metodologias Ativas. Florianópolis: Contexto Digital, 2017.

ENS, Romilda Teodora. Relação Professor, Aluno, Tecnologia: um espaço para o saber, o saber fazer, o saber conviver e o saber ser. Revista Digital da CVA, RICESU, v. 1, n. 3, fev. 2002.

FAUSTINO, S. B. S. et al. A Gamificação e suas Potencialidades no Programa Residência Pedagógica. In: VI Congresso Nacional de Educação. Anais... Fortaleza: Editora Realize, 2019.

MARCONI, M. A.; LAKATOS, E. M. Metodologia Cientifica. São Paulo: Atlas, 2011.

MORAN, José Manuel. Mudando a Educação com Metodologias Ativas. In: Convergências Midiáticas, Educação e Cidadania: aproximações jovens. Coleção Mídias Contemporâneas, 2015.

MORAN, José Manuel. O Vídeo na Sala de Aula. In: Comunicação e Educação. São Paulo, v.2, p.27-35, 1995.

MOTA, A.; WERNER DA ROSA, C. Ensaio sobre Metodologias Ativas: reflexões e propostas. Revista Espaço Pedagógico, v. 25, n. 2, p. 261-276, 28 maio 2018.

MONTEIRO, A. O.; SANTOS, R. P. S. dos. A Importância da Aula de Campo na Formação dos Professores de Geografia. In: II Congresso Nacional de Educação. Anais... Campina Grande: Editora Realize, 2015.

NEVES, F. M. O.; FAUSTINO, S. B. S.; ARAÚJO, M. P. O Uso dos Objetos de Aprendizagem no Ensino de Algoritmos. In: V Congresso Nacional de Educação. Anais... Recife: Editora Realize, 2018.

OLIVEIRA, Claúdio de. TIC's na Educação: A utilização das tecnologias da informação e comunicação na aprendizagem do aluno. Pedagogia em Ação, v. 7, n. 1, Dez. 2015. ISSN 2175-7003.

PANIZZOLO, C. et al. Programa de Residência Pedagógica da Unifesp: avanços e desafios para a implantação de propostas inovadoras de estágio. In: Políticas de Formação Inicial e Continuada de Professores. XVI ENDIPE - Encontro Nacional de Didática e Práticas de Ensino. Anais... Campinas, 2012. 
PEIXOTO, Anderson Gomes. O Uso de Metodologias Ativas como Ferramenta de Potencialização da Aprendizagem de Diagramas de Caso de Uso. Periódico científico outras palavras. Brasília, v. 12, n. 2, 2016.

RIBEIRO, Ormezinda Maria. A Produção de Textos em uma Sala de Aula sem Paredes: Um desenho curricular em construção. In: MACHADO, Andreia de Bem et al.(Org.). Práticas Inovadoras em Metodologias Ativas. Florianópolis: Contexto Digital, 2017.

RICARDO, V. K. D. et al. Da Observação a Regência: Um olhar sobre o estágio docente em eletrônica digital. In: V Congresso Nacional de Educação. Anais... Recife: Editora Realize, 2018.

SALES, Eric de. O Documentário na Sala de Aula: uma verdade absoluta para o aluno? In: ANPUH - XXV Simpósio Nacional de História - Fortaleza, 2009.

SALOMÉ, Josélia Schwanka. A desumanização dos sentidos: um estudo sobre a arte na educação escolar brasileira nas últimas décadas do século XX. 2011. 233 p. Tese (doutorado) - Universidade Estadual de Campinas, Instituto de Artes, Campinas, SP.

SANT'ANNA, Neide da Fonseca P.; MATTOS, Francisco Roberto P.; COSTA, Christine Sertã. Formação continuada de professores: a experiência do Programa de Residência Docente no colégio PEDRO II. Educ. rev. [online]. 2015, vol. 31, n. 4, pp. 249-278.

SANTOS, H. R.; DOMINIQUINI, E. D. A Insustentabilidade da Obsolescência Programada: uma violação ao Meio Ambiente aos Direitos do Consumidor. In: XXIII Encontro Nacional do CONPEDI/UFSC - Florianópolis-SC. (Org.). DIREITO DO CONSUMIDOR. 1ed. Florianópolis: Funjab, 2014, v. 1, p. 51-67.

SANTOS, Josivaldo Constantino dos. Processos Participativos na Construção do Conhecimento em Sala de Aula. Cáceres, MT: UNEMAT Editora, 2003.

SAVIANI, Dermeval. Pedagogia Histórico-Crítica: Primeiras Aproximações. 9. ed. Campinas, SP: Autores Associados, 2005.

SEVERINO, Antônio Joaquim. Metodologia do Trabalho Cientifico. São Paulo: Cortez, 2007.

SENICIATO, T.; CAVASSAN, O. Aulas de Campo em Ambientes Naturais e Aprendizagem em Ciências - Um Estudo com Alunos do Ensino Fundamental. In: Ciência \& Educação, v. 10, n. 1, p. 133-147, 2004.

SILVA, A. G. da; BORGES, M. de L. Implicações de um Cenário Multigeracional no Ambiente de Trabalho: Diferenças, Desafios e Aprendizagem. In: IV Encontro de Gestão de Pessoas e Relações de Trabalho. Brasília, 2013. 
SILVA, Karolayne Gonçalves da. Residência Pedagógica: uma alternativa possível na formação inicial de professores de ciências e biologia na UFPR? Trabalho de Término do Curso de Ciências Biológicas da Universidade Federal do Paraná. Curitiba, 2015.

SILVA, K. A. C. P. da; CRUZ, S. P. A Residência Pedagógica na Formação de Professores: história, hegemonia e resistências. Momento: diálogos em educação, EISSN 2316-3100, v. 27, n. 2, p. 227-247, mai./ago, 2018.

SILVA, Maria Beatriz Oliveira da. "Prêt à jeter": Obsolescência programada e Teoria do Decrescimento frente ao Desenvolvimento e ao Consumo. In: Conpedi. (Org.). Livro do XXI CONPEDI, Direito e Sustentabilidade, p.5435-5451, 2012.

TARDIF, Maurice. Saberes Docentes e Formação Profissional. 5. ed. Petrópolis, RJ: Vozes, 2002.

TERRA. Especialistas apontam falhas em projeto de residência pedagógica. 2013. Disponível em: <https://www.terra.com.br/noticias/educacao/especialistasapontam-falhas-em-projeto-de-residencia-pedagogica,b29e3ac4ca061410VgnVCM200 00099cce b0aRCRD.html>. Acesso em: 11 out. 2019.

ZICHERMANN, G.; CUNNINGHAM, C. Gamification by design. Sebastopol: O’Reilly, 2011.

ZORATTO, F. M. M.; HORNES, K. L. Aula de Campo como Instrumento DidáticoPedagógico para o Ensino de Geografia. Paraná, 2014. 